\title{
Harmonic reduction in a boost-star three-phase single switch power factor correction circuit operating in discontinuous conduction mode
}

\begin{abstract}
A harmonic injection technique, which reduces the kine frequency harmonics of the single switch three-phase boost rectifier, is implemented. In this method, a periodic voltage is injected in the control circuit to vary the duty cycle of the rectifier switch -within a line cycle so that the fifth-order harmonic of the input current is reduced to meet the total harmonic distortion (THD) requirement. Since the injected voltage signal, which is proportional to the inverted ac component of the rectified three-phase line-to-line input voltages is employed; the injected duty cycle variations are naturally synchronized with the threephase line-to-neutral input voltages.
\end{abstract}

Keyword: Boost converter; Discontinuous conduction mode; Harmonic injection; Power factor correction; Threephase rectifier 